63.535 and 52.453 people, respectively. In the Gran Canaria South area there is no formal FLS.

An estimate of the number of cases of fracture attended in FLS and that was still under treatment in septiembre 2016 was calculated.

Results: The total expenditure on prescriptions for osteoporosis in 2016 (January to September) in the North area was $1,226,702 €$, while in the South area it was $1,069,606 €$ (a 14\% higher in the North area). The expenditure in 2016 for group II (bisphosphonates and equivalents) was $799,840 €$ and $656,301 €$ respectively $(22 \%$ higher in the North area). The evolution of the percentage of total expenditure in osteoporosis for the North area in relation to the total of Gran Canaria was the following: $53.6 \%$ in $2011 ; 54.2 \%$ in $2012 ; 54.4 \%$ in $2013 ; 54.3 \%$ in $2014 ; 53.4 \%$ in 2014 and $53.4 \%$ in 2016 (Figure). For group II drugs, the percentage of 55\% for the North area did not change between 2011 and 2016 . The number of drug prescriptions for group I was 7,551 units in the North area and 7,732 in the South area. For group II, the figures were 3,917 units in the North area and 2,873 units in the South area. That is, the prescription of group I drugs in the January-September 2016 period was similar in both areas $(2 \%$ higher in the South area), while for Group II it was 36\% higher in the North area, being this difference stable between 2011 and 2016 .

Between 2012 and 2016, 1,297 patients have been evaluated in the FLS, of which $75 \%$ have indication of bisphosphonate or equivalents. The average adherence to treatment at 12 and 24 months is $70 \%$ (1). The estimate is that approximately 681 patients $(17 \%)$ of the 3,917 who receive a drug from group II in the North area in October 2016 derivates from the FLS.

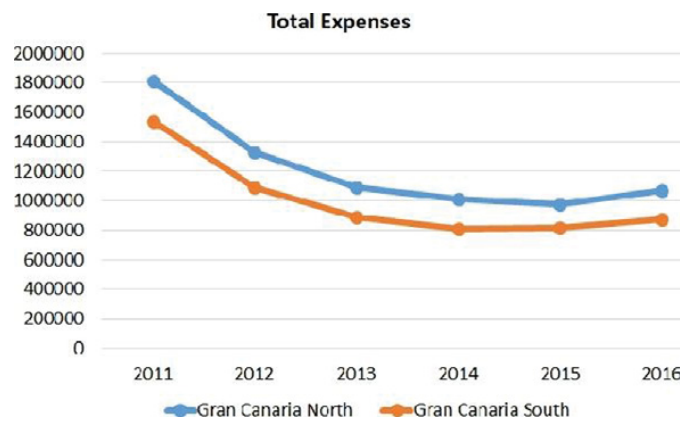

Conclusions: The implantation of a FLS, despite supposing around $16 \%$ of the percentage of patients treated with bisphosphonates and equivalents in the health area Gran Canaria North derivates from the FLS has not led to an increase in pharmaceutical expenditure for osteoporosis. We believe that one of the reasons for the non-increase in spending is the rational use of drugs for osteoporosis. References:

[1] Naranjo A et al. Osteoporos Int. 2015;11:2579.

Disclosure of Interest: None declared

DOI: 10.1136/annrheumdis-2017-eular.1485

\section{FRI0540 EVALUATION OF BONE QUALITY USING THE NEW TRABECULAR BONE SCORE (TBS) TOOL IN RHEUMATOID ARTHRITIS PATIENTS}

A. Casabella ${ }^{1}$, A. Sulli ${ }^{1}$, C. Seriolo ${ }^{2}$, G. Botticella ${ }^{2}$, L. Molfetta ${ }^{2}$, M. Cutolo ${ }^{1}$, S. Paolino ${ }^{1}$, B. Ruaro ${ }^{1}$. ${ }^{1}$ Research Laboratory and Academic Division of Clinical Rheumatology, Department of Internal Medicine, University of Genova, IRCCS AOU San Martino; ${ }^{2}$ Osteoporosis, Bone and Joint Disease Researc Center, CROPO, Di.M.I., University of Genova, Genoa, Italy

Background: Patients affected by Rheumatoid Arthritis (RA) show an increased risk of low bone mass, as a result of multi-systemic disorders including toxic drug, low vitamin D levels and physical inactivity. Trabecular Bone Score (TBS), is an index extracted from the dual-energy X-ray absorptiometry (DXA) images, that provides an indirect measurement (Score) of bone axial microarchitecture and allows to get information about bone quality $(1,2)$.

Objectives: The aim of this investigation was to evaluate bone quality in RA patients (high risk population) receiving vitamin $D$ supplementation from at least 3 month, using the TBS.

Methods: 108 female patients (mean age $61 \pm 8$ years) affected by RA and 60 age- matched controls (CNT) (mean age $64 \pm 11$ years) were enrolled. Bone Mineral Density (BMD, $\mathrm{g} / \mathrm{cm}^{2}$ ) of the lumbar spine (L1-L4) was analyzed using a DXA scan (GE,Lunar Prodigy). Lumbar spine TBS (TBS iNsight Medimaps) was derived for each spine DXA examination. All patients were evaluated for serum 25 hydroxyvitamin $\mathrm{D}(25(\mathrm{OH}) \mathrm{D})$ concentrations.

Results: 78 RA patients $(80 \%)$ presented a bone loss that was significantly lower when compared with control group $(p<0.001)$. Likewise, lumbar spine TBS score was found significantly lower in RA patients compared with CNT $(p<0.001)$. Finally, RA patients showed lower $25(\mathrm{OH}) \mathrm{D}$ concentrations $(18.4 \pm 1.3 \mathrm{ng} / \mathrm{ml})$ than CNT $(26.2 \pm 0.9 \mathrm{ng} / \mathrm{ml} ; \mathrm{p}<0.04)$.

Conclusions: This study shows in RA patients a reduction of TBS values that seem placed side by side with reduced BMD values and $25(\mathrm{OH}) \mathrm{D}$ serum concentrations. Therefore, TBS could become a new and safe diagnostic tool for the quantification of the bone quality and related osteoporosis, in chronic systemic inflammatory rheumatic diseases, such as RA.

References:

[1] Sinigaglia L, et al. Rheum Dis Clin North Am. 2006;32:631-58.

[2] Avouac J, et al. Arthritis Care Res 2012;64:1871-8.

Disclosure of Interest: None declared

DOI: 10.1136/annrheumdis-2017-eular.6126

\section{FRI0541 RELATIONSHIP BETWEEN CHRONIC PERIODONTITIS AND BONE MINERAL DENSITY IN A CASE-CONTROL STUDY OF PATIENTS WITH RHEUMATOID ARTHRITIS AND NON-INFLAMMATORY JOINT DISEASE}

J.L. Garnier Rodríguez ${ }^{1}$, J. González Febles ${ }^{2}$, S. Dadlani ${ }^{1}$, M.A. Gómez ${ }^{3}$, A. González Díaz ${ }^{3}$, L. Expósito Pérez ${ }^{4}$, E. Trujillo ${ }^{4}$, M. García González ${ }^{4}$, B. Rodríguez-Lozano ${ }^{4}$. ${ }^{1}$ Odontology/Periodontology, Dental Clinic Dr Garnier, Santa Cruz de Tenerife; ${ }^{2}$ Periodontology, UCM, Madrid; ${ }^{3}$ Nuclear Medicine Department; ${ }^{4}$ Rheumatology, Hospital Universitario Canarias, Tenerife, Spain

Background: The association between two chronic inflammatory diseases such as rheumatoid arthritis (RA) and periodontitis (PD) may be explained by causal and noncausal pathways. A possible mechanism in the increased PD observed in patients with RA is systemic bone loss due to the inflammatory process itself among others factors. Several studies have reported associations between OP and PD, not confirmed in other studies.

Objectives: 1.To determine whether OP is associated with PD and with PD severity.

Methods: Observational cross-sectional, case-control study of RA patients $\geq 18$ y.o. meeting ACR/EULAR 2010 criteria for RA in a Rheumatology Dept. and a control group with a non-inflammatory joint disease, with at least 4 teeth, without dental prophylaxis or antibiotic intake 6 months before. Socio-demographic and anthropometric variables with smoking status,Graffar scale, stress level, annual dental prophylaxis, and co-morbidities such as diabetes mellitus (DM), dyslipidemia (DS), ischemic cardiovascular disease (ICD) and history of lowimpact fractures. Dual-energy $x$-ray absorptiometry (DXA) $\left(\mathrm{g} / \mathrm{cm}^{2}\right)$ was performed with a DXA LUNAR (GE HealthCare) in lumbar spine and femoral neck. Periodontal Variables included plaque index, bleeding on probing, probing pocket depth, recession, clinical attachment level (CAL). Full mouth CAL and periapical $\mathrm{x}$-rays were taken. CAL was classified according to the European Workshop in 2005 (Tonetti), into level 0 (absence), TL1 (mild), TL2 (severe). Statistical Analysis: t-student test, Kruskal Wallis, Chi-square with Stata 13.1.

Results: We studied 344 patients: 187 RA (147 F/40 M) and 157control $(101 \mathrm{~F} / 56 \mathrm{M})$. Both groups were comparable in age 54.9 (17.9) y.o., body mass index 27.8 (4.6), stress level, DM and ICD. Differences in gender (>no. of males in controls), socioeconomic status (lower level in RA), > no. of current and former smokers RA (19.2\%vs $8.9 \% / 24.6 \%$ vs $11.5 \%)$,OP (23.4\% RA vs $7.8 \%)$, DS (hipertrygliceridemia $11.2 \%$ RA vs $4.4 \%$ ). PD was found in $97.3 \%$ of RA patients vs $66.2 \%$ of controls. DEXA was performed in 303 patients: $163 \mathrm{RA} / 140$ controls that showed OP in $38(23.3 \%)$ and $13(9.3 \%)$ of RA and control groups as well as osteopenia in $47(32.4 \%)$ and $16(11.3 \%)$ respectively $(p<0.001) ; 81 \%$ of these patients presented PD. There was association between PD and OP/osteopenia, so patients with PD had greater abnormal BMD $88 \%$ vs $76.3 \%$ with normal BMD; patients without PD showed greater normal BMD with statistically significant difference $(23.7 \%$ vs $11.1 \%)(p=0.008)$.

Conclusions: 1 . PD was observed in $81 \%$ of the patients evaluated with BMD; of these, $89 \%$ had OP/ osteopenia, and among the patients without PD a significant normal BMD predominated. 2. PD was found in $97 \%$ of RA patients versus $66 \%$ of controls; similarly OP was present in $23.3 \%$ of RA patients versus $9.3 \%$ of controls, with the diference being significant. 3 . There was no association between BMD and PD severity.

Disclosure of Interest: None declared

DOI: 10.1136/annrheumdis-2017-eular.5485

\section{FRI0542 PREVALENCE OF VERTEBRAL BODY DEFORMITIES RELATED TO OSTEOPOROSIS IN PATIENTS WITH NON-TRAUMATIC LUMBAR OR DORSAL ACUTE PAIN}

C.A. Guillen-Astete, C. Pijoán-Moratalla, J.R. Quiñones-Torres. Rheumatology Department, Ramon y Cajal University Hospital, Madrid, Spain

Background: Presence of vertebral body deformities is considered a relevant issue in order to chose a particular treatment in patients with osteoporosis. However, only remarcable deformities are properly identified and registred while those, less striking can just be unnoticed in radiological studies not related to osteporosis studies. One of the most usual radiographic study of the axial skeleton is the lumbar and dorsal acute pain. This group of patients is, indeed, suitable stablish proportions of any grade of vertebral body deformities according to the Genant scale.

Objectives: The goal of present study is to determine prevalence of vertebral body deformities in postmenopausial patients radiologically assessed due to lumbar or dorsal non traumatic related pain.

Methods: We performed a simple randomization of the registries of female patients with 65 years old or more who consulted due to dorsal or lumbar 